\section{Effective Environmental Factors for Reducing Children's Fear in Children's Hospital: Using Parent's Attitudes}

Sara Nourmusavi Nasab* Amir Reza Karimi Azeri ** Seyedjalil Mirbazel ${ }^{\star \star \star}$

\begin{abstract}
\section{Purpose}

Getting sick and getting into an unfamiliar environment in the hospital makes children fear, discomfort and is considered as a very common stressor in such setting. Poor design of hospital environments can exacerbate behavioral disorders, as well as fear and anxiety in individuals. The main purpose of this study is to investigate and address the needs and preferences of children regarding the design of therapeutic environments.
\end{abstract}

\section{Design/Methodology/Approach}

The desk research method was used and data was collected through a questionnaire given to the parents of children in 17th Shahrivar Children's Hospital in Rasht city, Northern Iran. After the data of the questionnaires was collected, it was analyzed through spss22 software. Descriptive statistics (charts, mean ...) were used to analyze the data. Due to the nonparametric nature of the data, Spearman test was used in order to measure the correlation of variables.

\section{Findings}

The results showed that the components of entertainment and play, natural light, the presence of green space, cheerful atmosphere and the presence of family are among the most important environmental
Keywords: Children, children's hospital, fear reduction, environmental factors

${ }^{*}$ Architecture and Art Faculty, University of Guilan, Rasht, Iran. (Principal contact for editorial correspondence.)

Email: saranoormousavinasab@gmail.co $\mathrm{m}$

ORCID No: https://orcid.org/00000002-1883-8042

${ }^{*}$ Associate Professor, Architecture and art faculty, University of Guilan, Rasht, Iran.

Email: mirreza_karimiazeri@guilan.ac.ir ORCID No: https://orcid.org/00000002-1551-8895

${ }^{* * *}$ Lecturer. Architecture and art faculty, University of Guilan, Rasht, Iran. Email: mirbazel1337@yahoo.com ORCID No: https://orcid.org/00000002-5202-7964 
elements affecting the reduction of children's fears from the perspective of their parents.

\section{Research Limitations/Implications}

the lack of direct involvement of the child in the study process as well as the cultural and economic differences are the main limitation of this study.

\section{Originality/Value}

This study is the first study on the design of children's medical environment using the opinion of their parents in Iran and in this regard.

\section{INTRODUCTION}

Common stressors during childhood are sickness and hospitalization (Del Nord, 2006). For children, hospital settings stimulate different emotions, such as fear, anxiety, anger, sadness, loneliness, which can have adverse effects on children's physical, mental and social health (Birch et al.,2007; BsiriMoghaddam et al., 2011; Norton-Westwood, 2012; Wilson et al., 2010). There is ample evidence that children's anxiety increases during hospitalization and, in consequence, their health can be subconsciously affected (Dise-Lewis, 1988; Varni \& Katz, 1997). Children suffer from a variety of considerable concerns and fears during their stay: fear of being away from family; fear of being in an unknown place; treatment stage's fear as well as loss of privacy (Coyne, 2006). Anxiety and fear, in terms of children' unconsciousness can affect the children's behavior throughout their life. As e result, researchers are more interested to study negative emotions, such as fear, anxiety, and stress-related concerns which occur during illness (Thompson \& Venon, 1993). According to previous researches, being a fun place, Hospital can attract children. children want an environment where they can make friends and engage in entertaining activities (Fletcher et al., 2011). In addition, the presence of peers and parents alongside sick children gives them a sense of security and comfort (NortonWestwood, 2012). Previous studies about parents' perceptions of children's hospital environments have shown that one of the key elements is the physical quality of that environment, which should be quiet, clean and convenient while also providing adequate space and privacy (Pelander et al.,2007).

In the last fifty years, advances in medical technology have increased the level of design competence in the therapeutic spaces. Complexity in such buildings have increased. This complexity is the result of the multiplicity of units, abundance and the diversity of users and increase in the quality of medical technologies (Aydın, 2009). Now, in Iran, the situations of children's hospitals present a number of problems including lack of environmental facilities, inattention to the needs of children and the impact of the environment on their health condition. 
Today, children's hospitals acknowledge that they must provide support for the whole family. Compared to adult patients, the whole family will be involved when the child is hospitalized. Parents suffer as a result of their role as guardians and supporters of their child. Brothers and sisters of the child will also suffer because parents' attention is focused on the other. Since the mental state of children in the hospital is very important to help the healing process, identifying the elements of the children's hospital environment that lead to stress reduction can be an effective step in their recovery as well. Additionally, as the parents of children are directly involved in the treatment of their children, the purpose of this paper is to ask parents' opinions about their children's preferences for the ideal physical design of hospital built environments. The knowledge generated from this study helps designers and healthcare creators providing data that can be used in their design and operations decisions. And also it may improve the ability of healthcare providers to create environment that is congruent with the needs of parents and their children. This study will therefore address the following research questions.

- How important is the existence of environmental factors, such as; color, light, spatial layout, green space, scale and shape of hospital?

- How effective is the existence of amusement spaces in reducing child's fear?

- How important is the presence of the family next to the child?

\section{LITERATURE REVIEW}

By the 1960s, hospital buildings had focused more on hospital performance than patient experience (De Wilde \& Muylle, 2012). Until the 1990s, little information was available about hospital design, but through the decade, architects and interior designers tended to design based on existing information and knowledge based on research achievements in this field (Rubin, 1998). Kellman (1987), focuses on the scale structure (outer structure and interior design, vertical dimensions, furniture size and handle height), play areas, environmental issues (color, texture, light and acoustic). Eriksen (2000), reviewed some children's opinions about the hospital environment during study at a children Hospital. In this study, factors such as the ability to play, the use of cheerful colors, attractive decoration, the presence of green space, the proper dimensions of the furniture, the presence of private space are considered. Previous studies illustrated the influence of Parental involvement and partnership in healthcare environment on treatment of child patients as assistants (Coyne, 1995; Dudley \& Carr, 2004; Ygge \&Arnetz, 
2004). Ha and Park (2016) worked on a study with the aim of designing user-oriented children's hospital. In this study, user's needs were examined, especially by the help of their mothers and the nurses. The findings indicated that to improve the satisfaction of the mothers of ill children and the nurses, factors such as privacy, safety, accessibility should be considered.

In another study, children who used deviant techniques such as watching cartoons or listening to music reported less pain and anxiety (Sinha et al., 2006). A joint study about group play therapy impact on the rate of depression in children with cancer in Mahak Hospital in Tehran, showed that the game could be used as an effective solution by healthcare team members to help hospitalized children so that they could be helped in order to be prepared and tuned with the process of difficult treatments and tension associated with hospitalization procedure (Zareapour et al., 2009). In another research in a children hospital in Iran, children perspectives about ideal physical environment were extracted. The results of this article expressed that ill children prefer a hospital environment that provides appropriate recreational facilities for them. And at the same time, other environmental design factors such as light, green space, appropriate color and the possibility of parent's presence were important (Nasab et al.,2020). Below, some factors influencing children's perceived stress and fear in the environment of the hospital are summarized with their sources (Table 1).

Table 1: Factors influencing children's environment and stress in hospital

\begin{tabular}{|c|c|}
\hline References & Factors \\
\hline (Rollins, 2015)- (Shirani et al., 1986) & Family Partnership \\
\hline (Malkin, 1992) - (Bettelheim, 1976) & $\begin{array}{l}\text { Access to the outside } \\
\text { environment }\end{array}$ \\
\hline (Carpman \& Grant, 2001) - (Topf, 2000) & Routing and Readability \\
\hline (Kellman, 1987) & Scale \\
\hline (Malkin, 1992) - (Bettelheim, 1976) & Feel under control and care \\
\hline $\begin{array}{c}\text { (Rubin, 1998) - (Kellman, 1987) - (Rollins, } \\
\text { 2015) -(Lee et al., 2007) }\end{array}$ & light \\
\hline $\begin{array}{c}\text { (Rollins, 2015) - (Topf, 2000)- (Ulrich et al., } \\
\text { 2008) - (Mour, 2010) }\end{array}$ & Effect of green space design \\
\hline $\begin{array}{l}\text { (Shirani et al., 1986) - (Lee et al., 2007) } \\
\text { (Barlas et al., 2001) }\end{array}$ & $\begin{array}{l}\text { Create privacy controls and } \\
\text { privacy }\end{array}$ \\
\hline Malkin, 1992) - (Bettelheim, 1976) & Coordination \\
\hline (Frampton \& Charmel, 2009) & $\begin{array}{l}\text { See artistic and positive } \\
\text { images }\end{array}$ \\
\hline (Lee et al., 2007) & Availability and order \\
\hline (Shirani et al., 1986)- (Rollins, 2015) & Human interactions \\
\hline (Topf, 2000) - (Kellman, 1987) & Prevent unwanted sounds \\
\hline
\end{tabular}

In the following, the theoretical framework is expressed, on which the research method is written. 


\section{Stress and Child's Fear in the Hospital}

Seeing hospital settings of any size and form provides a frightening experience for each person (El Marsafawy, 2006). The unfamiliar environment of hospitals can be destructive and harmful to children which, in consequence, causes stress. For example, the problem of losing privacy due to the presence of multiple room (Larsen et al., 2014). According to Lee et al. (2007), "the physical environment affects the person's behavior, and positive experiences can help the person to overcome stress". The outcome of admission to hospital is anxiety for children, in which case, children react in three ways: protest, disappointment, and denial. Reduced interest in playing and collective activities, avoiding collapse and isolation, mischief, anger and lack of satisfaction are the responses of children admitted to hospital (Malkin, 1992). For children, stress signifies by stomach pain, sleeping problems, stools and infections (DeBord \& Sawyers, 1996). The following five main factors can boost stress in a child: 1- Disease, 2- Hospital admission, 3Physical - social environment of the hospital, 4- repetitive treatment processes, 5- pain Experience (Del Nord, 2006). A research in the environmental psychology field indicates that architectural factors such as motivation, plurality, diversity, complexity, novelty, sound, light, odor, colorization, crowding, apparent, visual, proximity, neighborhood, communication, readability, organization, Predictability, Signs, Paths, Distinctions, External Perspectives, Land Operations, Ambiguities, coordinated alignment of furniture and refreshment are perceptually related to both positive and negative stresses (Lee et al., 2007).

\section{Desirable Environmental Components for Children in Hospital Environment}

In the context of effective factors in the design of medical environments, in 1859, Florence Nightingale, in her book entitled "Hospital Writings," stated that design, lighting, ventilation are critical elements for accelerating patient recovery and reducing pressure (Ebneshahidi et al., 2011). In 1960, interior design was introduced as a major factor in hospital environmental planning (Morelli et al., 2007). The needs of hospitalized children include healthy eating, proper sleep in good conditions, and basic needs such as personal hygiene and physical care. Hospitalized children may not feel comfortable not only because of their illness, but also because of being away from their families. Also, they may respond to their disagreement over their age group (SilavUtkan, 2012). 


\section{The Importance of Light and Color in Children's Hospital Design}

Factors such as color and light can affect people's perceptions and responses to the environment in which they are present. In particular, these factors are important in the treatment environment and the patient's recovery process. Light can improve the quality of the overall experience of staff, visitors and especially patients in the hospital environment (Dalke et al., 2006). Kellman in his research emphasized on the effect of natural light on children's recovery and the reduction of effective feelings (Ebneshahidi et al., 2011). A research showed that the proper coloring of the environment is effective in creating a person's positive mood and comfort (Tofle et al., 2004). J. Coad and N. Coad (2008), conducted a research through interviews on children's preferences in the design and color of the hospital environment. They questioned some children's views in three color ranges: Pink-purple, Blue-Green and Orange-Yellow. The color mostly selected by children was between the color range of green and blue. Children over the age of 11 years had a darker range. Warm yellow-orange colors as well as the pink-purple colors had the lowest number of choices. Park (2009), in his research, concluded that, based on gender, girls were more likely to enjoy red and purple colors. Apart from the gender perspective, sick children often preferred blue and green, and had the slightest tendency to the white color.

\section{Positive Distractions' Role in Children's Hospital}

Positive distractions are related to environmental features that create "positive emotion and attract people's attention and their disturbing thoughts may be declined by that" (Devlin \& Arneill, 2003). Positive distractions help people overcome their stresses and tensions. Positive distraction involves distraction potential, including static stimuli such as pictorials, posters or nature paintings, active stimuli such as animals, music and elements that make people happy (Berman et al., 2008). The impact of positive distraction on the activity of children in two clinic waiting areas is examined by Pati and Nanda (2011). They concluded that distraction leads to a gentler behavior of children, which reflects its significant sedative effects. Also, the data indicated that the waiting time for children in hospitals can be risen by improving the environmental attractiveness.

\section{The Effect of Green Space in Children's Hospital}

A research has shown that the simulation of nature creates stress-reducing effects similar to what there is in nature (Berman et al., 2008). The most effective of these distractions is the ability of nature to improve and repair stress (Raanaas, 2012; 
Salonen et al., 2013). It was shown in a study that patients undergone surgery who could see the plants through window, when compared to those who couldn't, had a shorter hospital stay and reported more positive hospital experience (Ulrich et al., 2008). Also, the views of the windows that opened to the green space could have reduced the hospital's post-operative stay by 8.5 percent. In US hospitals, they are increasingly focusing on trees and taking care of them in order to improve their patients' recovery faster (Mour, 2010).

\section{The Importance of Way Finding in Children's Hospital}

Researchers found that stress due to losing one's path loss can contribute to frustration, increased blood pressure, headache, physical stress and fatigue (Carpman \& Grant, 2001). Hence, creating a readable environment can enhance the cognitive inhibition of users in terms of perceiving environmental results in better treatment outcomes. Due to complexity of their paths, hospitals, as a public place, have problems about way finding (Rousek \& Hallbeck, 2011). Proper way-finding in hospital design can be effective in increasing user satisfaction such as employees, visitors and, most importantly, the patient (Cooper, 2010). Being aware of surrounding environment leads to ease and safety (Cutting, 1996). By utilizing graphics and tactile communication way finding can be improved (Arthur \& Passini, 1992).

\section{The importance of family presence}

For decades, parental involvement has been considered as a supported philosophy for the continuity of care for children (Power \& Franck, 2008). The presence of parents can grow the sense of security of children (Norton-Westwood, 2012). Children's resources point to the fact that if one parent or both can be with their children, it is the most important factor that helps children to cope with a mental illness due to hospitalization. Parental presence also helps the child to more easily accept the daily work process of the hospital (Malkin, 1992).

\section{RESEARCH METHOD}

This research is purpose-oriented, applied. In terms of collecting data, it is a non-test descriptive study. Also, it was carried out as a sample case study. The measurement tools include: questionnaire and the software of social package for statistical analysis (SPSS22). The questionnaire consisted of 26 questions classified into 5 categories entitled "Mental relaxation, comfort, attractiveness, positive distraction and security." When developing the questionnaire, it was tried not to make them 
unobtrusive, ambiguous, directional, complex, duplicate, negative, and the concept of questions was completely clear.

Hivdah Shahrivar Hospital which is the only specialized pediatric children hospital in Rasht, is selected for this research. To estimate the sample size for the questionnaire the Morgan table is used (Krejcie \& Morgan,1970). Given the fact that about 140 people were visiting Hivdah Shahrivar hospital every day, and with respect to this table, 103 parents were being examined. The type of questionnaire is Questions in Closed Ended Format. This is an ideal format for calculation of statistical information which can be helpful in obtaining opinions about a subject. The format of Questions is Likert Questions which is helpful in analyzing Customers' feelings about a topic. Based on the theoretical foundations of the study, the effective variables in reducing environmental stress in hospital such as color, light, structure, green space, presence of parents, etc., were selected and used in designing the questions. After the questionnaire was developed and the sample size was determined, next step was to enter the field. After entering the field to reach the best solution and generalizability of the responses, 103 parents of the patients were randomly selected. In this way, first they were given a letter in which the purpose of data collection, needs for their cooperation in providing the required data, and confidentiality of the responses, were expressed. Then the questionnaires were distributed and each respondent helped in the response process.

\section{RESULTS}

Shahrivar Hospital is a Children's Specialized Hospital located in Rasht. This hospital has 170 beds. The only specialized medical unit of Rasht is this hospital. The spatial relationships and positioning of the building are shown in Figures 1, 2, and 3.

Figure 1. Ground floor space relations diagram (Authors).

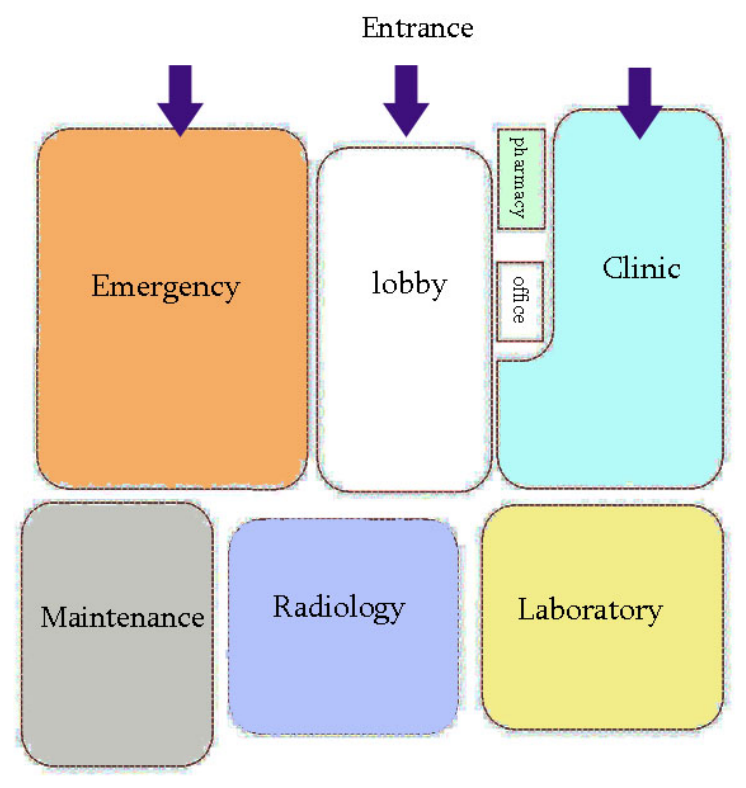


Effective Environmental Factors for Reducing Children's Fear in Children's Hospital: Using Parent's Attitudes
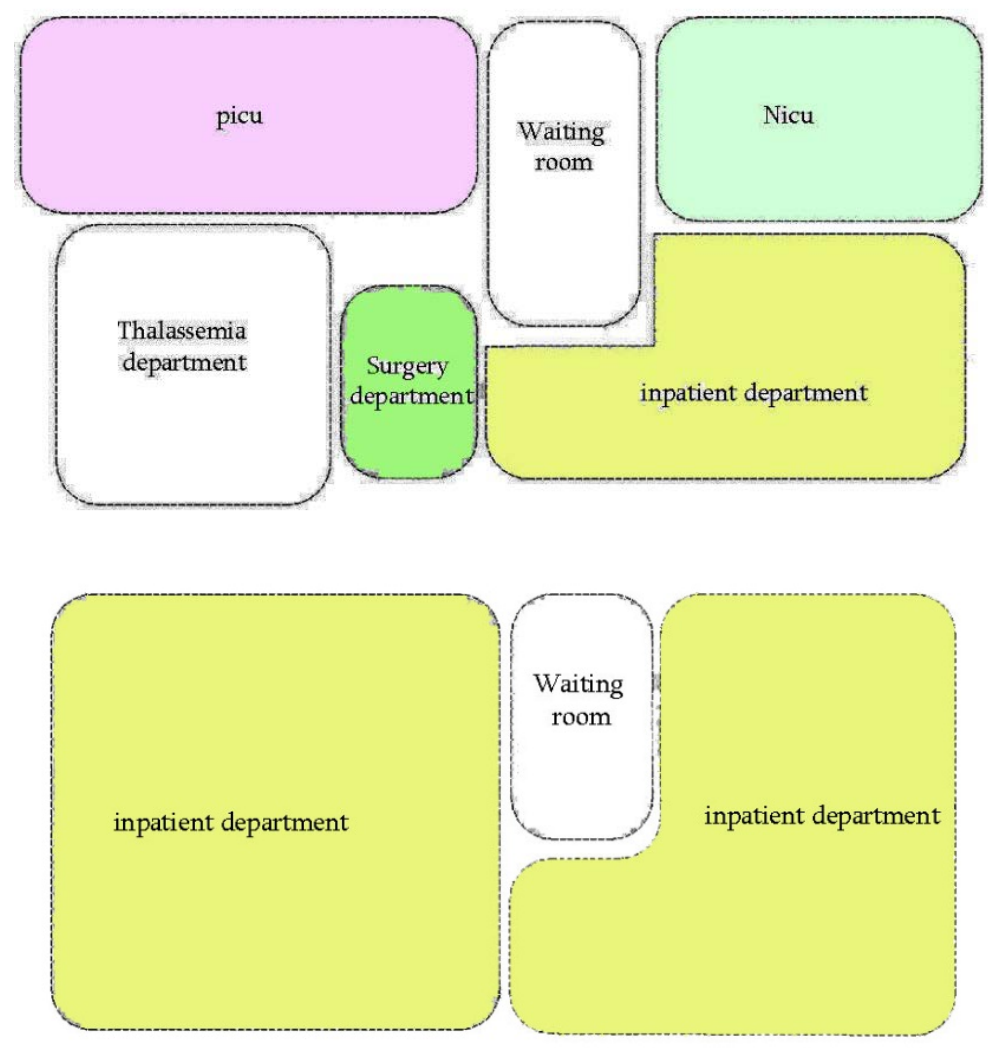

The current visual form of this hospital is illustrated in Figures 4, 5 and 6. No use of happy colors and green space in the environment, scattered space layout and inappropriate furniture can be seen in the pictures.
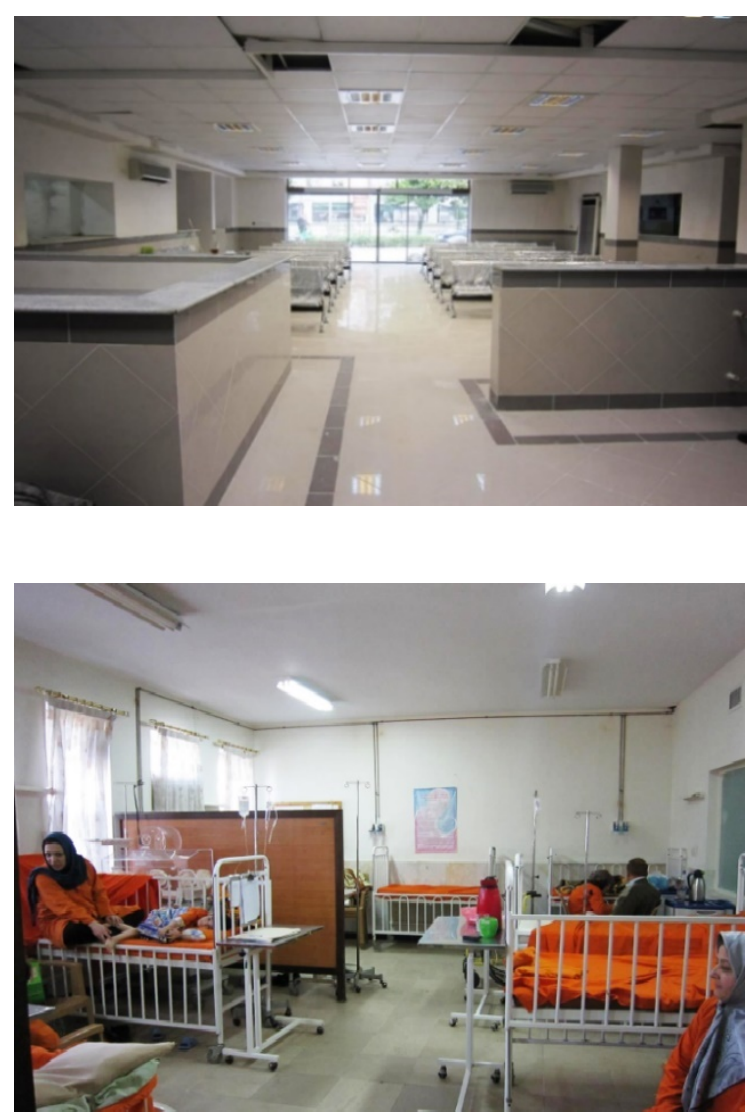

Figure 2. First floor space relations diagram (Authors).

Figure 3. Second floor space relations diagram (Authors).

Figure 4. Waiting room (Authors).

Figure 5. Patient room (Authors). 


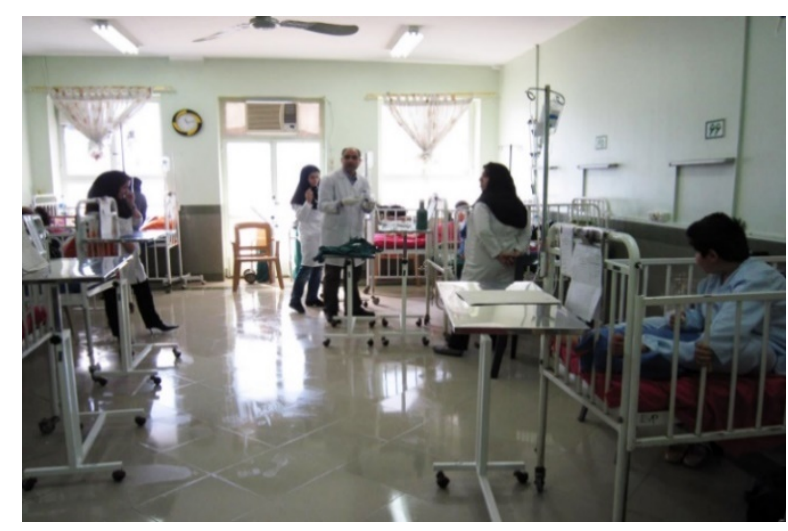

In order to measure the reliability of the research tool, the most popular instrument used by many researchers to assess the validity of the questionnaire is the Cronbach's alpha coefficient. Cronbach's alpha is one of the best analyzes for the reliability of research in the social and organizational sciences (Bonett \& Wright, 2015). This criterion was calculated by SPSS22 software and the questionnaire had a reliability of more than $70 \%$ which indicates a satisfactory level of reliability. So, it can be said that the questionnaire has been able to measure the subject. Therefore, the research has a good internal consistency. Depending on the type of research and its data, the method for data analysis is logically based on inductive method. Descriptive statistics (charts, mean ...) were used to analyze the data. For this purpose, the answers of the questions were entered into SPSS22 software and the graphs and statistical results were extracted and analyzed. The most important option in the subset of the factors are the question 2 and the 21st question, namely the presence of at least one of the parents at full time (question 2) and the possibility of having a game room in each part of the hospital (question 21) with an average of 4.5. The least important question is question 5 expressing presence of religious elements with an average of 3.2 (Table 2).

Table 2: The effect of environmental components on reducing children's fear in the hospital from parents' perspectives, with the questions separated

\begin{tabular}{|l|l|}
\hline \multicolumn{2}{|l|}{ Factor: Mental relaxation } \\
\hline Question 1 & Average $=4.6$ Mode $=5$ \\
\hline Question 2 & Average $=4.6$ Mode $=5$ \\
\hline Question 3 & Average $=4.6$ Mode $=5$ \\
\hline Question 4 & Average $=4.6$ Mode $=4$ \\
\hline Question 5 & Average $=4.6$ Mode $=3$ \\
\hline Factor: comfort \\
\hline Question6 & Average $=4.3$ Mode $=4$ \\
\hline Question7 & Average $=4.4$ Mode $=4$ \\
\hline Question8 & Average $=4.3$ Mode $=4$ \\
\hline Question9 & Average $=4.3$ Mode $=4$ \\
\hline Question10 & Average $=4.3$ Mode $=4$ \\
\hline Factor: attractiveness \\
\hline
\end{tabular}


Effective Environmental Factors for Reducing Children's Fear in Children's Hospital: Using Parent's Attitudes

\begin{tabular}{|c|l|}
\hline Question11 & Average $=4.3$ Mode $=4$ \\
\hline Question12 & Average $=4.2$ Mode $=4$ \\
\hline Question13 & Average $=4.3$ Mode $=4$ \\
\hline Question14 & Average $=4.3$ Mode $=4$ \\
\hline Question15 & Average $=4.1$ Mode $=4$ \\
\hline Question16 & Average $=4.2$ Mode $=4$ \\
\hline Factor: Positive distraction \\
\hline Question17 & Average $=4.4$ Mode $=4$ \\
\hline Question18 & Average $=4.2$ Mode $=4$ \\
\hline Question19 & Average $=4.4$ Mode $=4$ \\
\hline Question20 & Average $=4.4$ Mode $=4$ \\
\hline Question21 & Average $=4.5$ Mode $=5$ \\
\hline Question22 & Average $=4.4$ Mode $=4$ \\
\hline Factor: security \\
\hline Question17 & Average $=4.3$ Mode $=4$ \\
\hline Question17 & Average $=4.2$ Mode $=4$ \\
\hline Question17 & Average $=4.2$ Mode $=4$ \\
\hline Question17 & Average $=4$ Mode $=4$ \\
\hline
\end{tabular}

According to the descriptive statistics, among five factors of mental relaxation, comfort, attractiveness, positive distraction and security, comfort and positive distraction with the average of 4.3 were more important than other factors (Table 3 and Figure 7).

Table 3: The effect of environmental components on reducing children's fear in the hospital from parents' perspectives

\begin{tabular}{|l|l|}
\hline Factor: Mental relaxation & Average $=4.1$ mode $=4$ \\
\hline Factor: comfort & Average $=4.3$ mode $=4$ \\
\hline Factor: attractiveness & Average $=4.2$ mode $=4$ \\
\hline Factor: Positive distraction & Average $=4.3$ mode $=4$ \\
\hline Factor: security & Average $=4.2$ mode $=5$ \\
\hline
\end{tabular}

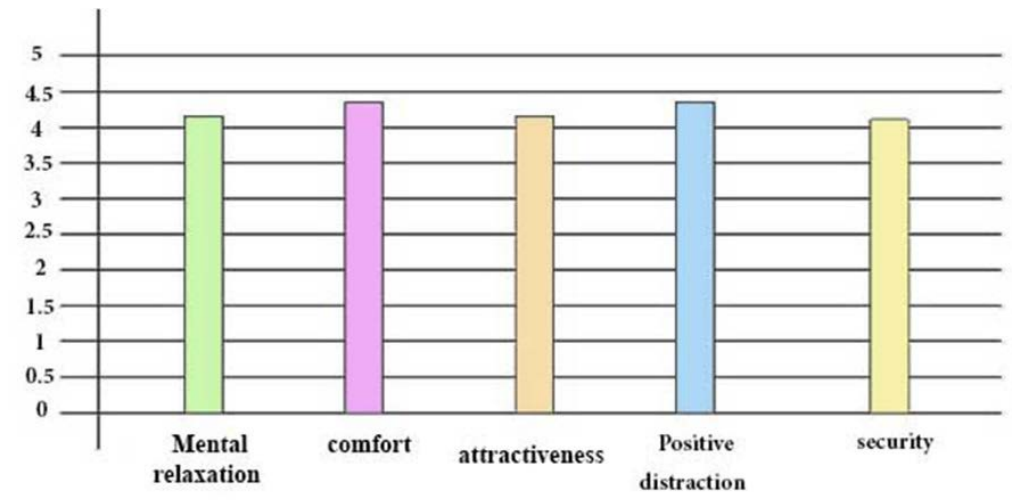

The Kolmogorov-Smirnov test which is a much used goodnessof-fit test, is often employed to test normality (Steinskog et al., 2007). In the following, with the Kolmogorov-Smirnov test, the value of "P" was less than 5 hundred, suggesting that the distribution of data is not normal. Hence nonparametric testing should be used. Due to the rank of variables, Spearman test is used to measure the correlation of variables. Spearman's Rho is a
Figure 7. The average impact of environmental factors on reducing the children's fears in the hospital from the perspective of parents (Authors). 
non-parametric test which is appropriate method to examine the strength of association between two variables, where the value $r$ $=1$ means a perfect positive correlation and the value $r=-1$ means a perfect negative correlation (Allen, 2017). According to Spearman's analysis, by which the correlation between the variables is determined, there is a high correlation between the mental relaxation factor of the happy colors and the green space, which means that the more increase the values of these two factors, the more increases the calmness. The factor of religious elements has had the least correlation value (Table 4). For comfort element, the presence of sufficient lightning had the highest correlation (Table 4). For the factor of attractiveness, elements hanging from the ceiling and the Hospital Curve structure were highly correlated, which suggest these factors are more important (Table 5). For distraction, the presence of artificial light had a high degree of correlation, and the creation of art workshops and the existence of television had a small correlation. For security, the readability was more correlated (Table 6). In general, the factors of artificial light, play room, water elements, elements hanging from the ceiling, outdoor play, hospital curve structure, ventilation, adequate lighting, green spaces and happy colors were more important ones. The factors of religious elements, noise reduction, television and art workshops were weaker factors.

Table 4: Correlation between variables of mental relaxation and standard spaces factors

\begin{tabular}{|c|c|}
\hline \multicolumn{2}{|l|}{ Factor: Mental relaxation } \\
\hline Religious elements & $\begin{array}{l}\text { correlation coefficient }=0.043 \\
\text { sig }=0.666\end{array}$ \\
\hline Happy colors & $\begin{array}{l}\text { correlation coefficient }=0.8 \\
\text { sig }=0.003\end{array}$ \\
\hline green space & $\begin{array}{l}\text { correlation coefficient }=0.73 \\
\text { sig }=0.002\end{array}$ \\
\hline The presence of family & $\begin{array}{l}\text { correlation coefficient }=0.212 \\
\text { sig }=0.032\end{array}$ \\
\hline \multicolumn{2}{|l|}{ Factor: comfort } \\
\hline Proper ventilation & $\begin{array}{l}\text { correlation coefficient }=0.64 \\
\text { sig }=0.046\end{array}$ \\
\hline Enough lighting & $\begin{array}{l}\text { correlation coefficient }=0.71 \\
s i g=0.032\end{array}$ \\
\hline $\begin{array}{l}\text { Furniture with scale and size of } \\
\text { the child }\end{array}$ & $\begin{array}{l}\text { correlation coefficient }=0.523 \\
\text { sig }=0.063\end{array}$ \\
\hline Noise reduction & $\begin{array}{l}\text { correlation coefficient }=0.186 \\
\text { sig }=0.06\end{array}$ \\
\hline
\end{tabular}


Effective Environmental Factors for Reducing Children's Fear in Children's Hospital: Using Parent's Attitudes

Table 5: Correlation between variables of attractiveness and positive factors

\begin{tabular}{|c|c|}
\hline Factor: attractiveness & \\
\hline Children Handcrafted & $\begin{array}{l}\text { correlation coefficient }=0.601 \\
\text { sig }=0.051\end{array}$ \\
\hline Hospital Curve structure & $\begin{array}{l}\text { correlation coefficient }=0.854 \\
\text { sig }=0.018\end{array}$ \\
\hline The playing field is outdoors & $\begin{array}{l}\text { correlation coefficient }=0.666 \\
\text { sig }=0.044\end{array}$ \\
\hline $\begin{array}{c}\text { Elements hanging from the } \\
\text { ceiling }\end{array}$ & $\begin{array}{l}\text { correlation coefficient }=0.842 \\
\text { sig }=0.020\end{array}$ \\
\hline Water elements & $\begin{array}{l}\text { correlation coefficient }=0.665 \\
\text { sig }=0.041\end{array}$ \\
\hline Factor: Positive distraction & \\
\hline Art workshops & $\begin{array}{l}\text { correlation coefficient }=0.154 \\
\text { sig }=0.141\end{array}$ \\
\hline Game room & $\begin{array}{l}\text { correlation coefficient }=0.627 \\
\text { sig }=0.048\end{array}$ \\
\hline Computer Game Features & $\begin{array}{l}\text { correlation coefficient }=0.512 \\
\text { sig }=0.065\end{array}$ \\
\hline Existence of television & $\begin{array}{l}\text { correlation coefficient }=0.141 \\
\text { sig }=0.138\end{array}$ \\
\hline Artificial light & $\begin{array}{l}\text { correlation coefficient }=0.954 \\
\text { sig }=-0.06\end{array}$ \\
\hline
\end{tabular}

Table 6: Investigating the correlation between security factor variables

\begin{tabular}{|c|l|}
\hline Factor: Security & $\begin{array}{l}\text { correlation coefficient }=0.334 \\
\text { sig }=0.094\end{array}$ \\
\hline $\begin{array}{c}\text { The closeness of the nursing } \\
\text { station to the hospital room }\end{array}$ & $\begin{array}{l}\text { correlation coefficient }=0.206 \\
\text { sig }=0.037\end{array}$ \\
\hline Independent admission room & $\begin{array}{l}\text { correlation coefficient }=0.214 \\
\text { sig= } 0.117\end{array}$ \\
\hline
\end{tabular}

\section{DISCUSSION}

The findings demonstrate that factors like adequate lighting, play room, water elements, outdoor play, hospital structure, ventilation, green spaces and happy colors, can be ideal environmental elements providing suitable environment for children.

In this study, comfort and positive distraction with an average of 4.3 are more important than other ones. Previous studies have also highlighted the significance of positive distraction. Other research done by Pati and Nanda (2011), has also expressed that positive distraction leads to gentle behavior of children.

The use of happy colors is the most important factor for the subjective sense of mental relaxation. Other studies have also suggested that the use of happy color in the environment can lead to positive effect on children's mood (J. Coad and N. Coad, 2008).

Lighting as an environmental factor in this research, is indicted by other researchers in hospital environment as well. Light improves the quality of patients, staff and visitor's overall 
experience in the hospital environment (Dalke et al., 2006). Readability is another important environmental element. Other studies have also suggested that readability have positive effect on stress reduction in hospital environment (Lee et al., 2007).

\section{CONCLUSION}

This study was conducted as a scientific research to transform children's needs into design by examining their parents' responses about their children's needs in hospital setting. Considering the results of the attitude screening questionnaire from the parents of the sick children as well as library studies done through desk research method, the elaboration of the features that can be considered for designing children's hospital environments is as follows:

- Of the four factors of mental relaxation, attractiveness, positive distraction and security, comfort and positive distraction with an average of 4.3 are more important than other ones.

- The most important factor for the subjective sense of mental relaxation is the use of happy colors in the environmental design of hospital.

- $\quad$ The most important factor for the environmental comfort is the presence of adequate light in the environment.

- The most important factor for the subset of attractiveness is the use of curve structures in the design of the environment.

- The most important factor for the subset of positive distraction is the use of artificial light.

- The most important factor for the security subset is readability in routing.

In conclusion, according to the findings, the presence of happy colors, sufficient lighting, elements hanging from the ceiling, hospital curve structure and artificial light, had a correlation of more than 0.7 , suggesting that these factors are more important. However, the relative importance of factors may vary (for example, by culture).

This study provides nurses, architects, clinicians and other stakeholders with insight into what an ideal healthcare environment should constitute, from the perspective of parents. And if these design strategies are used, it seems to affect the quality of life of hospitalized children.

An important limitation of this research is the lack of direct involvement of the child in the study process. In other words, there may be differences between parents and children view. Another major limitation of this study is the cultural and 
economic differences as well as the existence of different living conditions in different societies. Each of these factors can be effective in prioritizing environmental factors. It seems that in future research, the impact of culture, economy and living conditions of people in different geographical areas can be examined.

\section{ACKNOWLEDGMENT}

This article is an excerpt from Sara Nourmusavi nasab's Master Dissertaion titled " The design of the children specialist health center in Rasht with an approach to reduce the fear of the environment utilizing user opinions ", directed by Dr Amir Reza Karimi Azeri, Seyedjalil Mirbazel at Gilan University.

\section{REFERENCES}

Allen, M. (Ed.). (2017). The SAGE Encyclopedia of Communication Research Methods. SAGE Publications.

Arthur, P., \& Passini, R. (1992), Wayfinding: People, Signs, and Architecture.

Aydın, D. (2009). Hastane Mimarisi, lkeler ve Ölçütler. TMMOB Mimarlar Odası Konya Şubesi Yayını, Konya.

Barlas, D., Sama, A. E., Ward, M. F., \& Lesser, M. L. (2001). "Comparison of the auditory and visual privacy of emergency department treatment areas with curtains versus those with solid walls", Annals of Emergency Medicine, 38(2): 135-139.

Berman, M. G., Jonides, J., \& Kaplan, S. (2008). "The cognitive benefits of interacting with nature", Psychological science, 19(12): 1207-1212.

Bettelheim, B. (1976). Bruno Bettelheim. Center for Cassette Studies.

Birch, J., Curtis, P., \& James, A. (2007). "Sense and sensibilities: in search of the child-friendly hospital", Built Environment, 33(4): 405-416.

Bonett, D. G., \& Wright, T. A. (2015). Cronbach's alpha reliability: Interval estimation, hypothesis testing, and sample size planning. Journal of Organizational Behavior, 36(1): 3-15.

Bsiri-Moghaddam, K., Basiri-Moghaddam, M., Sadeghmoghaddam, L., \& Ahmadi, F. (2011). "The concept of hospitalization of children from the view point of parents and children", Iranian Journal of Pediatrics, 21(2): 201.

Carpman, J. R., \& Grant, M. A. (2016). Design that cares: Planning health facilities for patients and visitors (Vol. 142). John Wiley \& Sons. 
Coad, J., \& Coad, N. (2008). "Children and young people's preference of thematic design and colour for their hospital environment", Journal of Child Health Care, 12(1): 33-48.

Cooper, R. (2010). "Successful signage: how hospitals have solved wayfinding challenges. Health facilities management, 23(11): 27-30.

Coyne, I. T. (1995). "Partnership in care: parents' views of participation in their hospitalized child's care", Journal of Clinical Nursing, 4(2): 71-79.

Coyne, I. (2006). "Children's experiences of hospitalization", Journal of Child Health care, 10(4): 326-336.

Cutting, J. E. (1996). Wayfinding from multiple sources of local information in retinal flow.

Dalke, H., Little, J., Niemann, E., Camgoz, N., Steadman, G., Hill, S., \& Stott, L. (2006). "Colour and lighting in hospital design", Optics \& Laser Technology, 38(4-6): 343-365.

DeBord, K., \& Sawyers, J. (1996, February). The effects of training on the quality of family child care for those associated with and not associated with professional child care organizations. In Child and youth care forum (Vol. 25, No. 1, pp. 7-15). Kluwer Academic Publishers-Human Sciences Press.

Del Nord, R. (2006). Environmental stress prevention in children's hospital design. Milano: Motta Architettura, 324-5.

Devlin, A. S., \& Arneill, A. B. (2003). "Health care environments and patient outcomes: A review of the literature", Environment and Behavior, 35(5): 665-694.

DE Wilde, L., \& Muylle, J. (2012), Dragende Muren: over het ontwerpen van een zorgende ziekenhuisomgeving voor kinderen. Gent, MER. Paper Kunsthalle.

Dise-Lewis, J. E. (1988). The life events and coping inventory: an assessment of stress in children. Psychosomatic medicine.

Dudley, S. K., \& Carr, J. M. (2004). "Vigilance: the experience of parents staying at the bedside of hospitalized children", Journal of Pediatric Nursing, 19(4): 267-275.

Ebneshahidi, m., Hojjat,I., Tabaeian,S.m., \& Mazaheri,T.(2011), The study of environmental needs of patients and disabled persons with 6 to 12 years old based on their experiences, to increase the quality of pediatric treatment spaces in Isfahan city: aphenomenological atudy.

El Marsafawy, H. (2006). Design for effective and affective medical environments (Doctoral dissertation). 
Eriksen, A. (2000). Participatory planning and design of a new children's hospital. the International Academy for Design and Health.

Frampton, S. B., \& Charmel, P. A. (Eds.). (2009). Putting patients first: best practices in patient-centered care (Vol. 38). John Wiley \& Sons.

Fletcher, T., Glasper, A., Prudhoe, G., Battrick, C., Coles, L., Weaver, K., \& Ireland, L. (2011). "Building the future: children's views on nurses and hospital care", British Journal of Nursing, 20(1): 39-45.

Ha, J. M., \& Park, S. B. (2016). “User Evaluation for User-Oriented Children's Hospital Design-Focused on the Mothers of Child Inpatients and the Nurses", Korean Institute of Interior Design Journal, 25(1): 192-200.

Kellman, N. (1987). "Considering Children's Special Needs in the Layout and Scale of Pediatrics Hospitals", Children's Environments Quarterly, 3-5.

Krejcie, R. V., \& Morgan, D. W. (1970). “Determining sample size for research activities", Educational and Psychological Measurement, 30(3): 607-610.

Larsen, L. S., Larsen, B. H., \& Birkelund, R. (2014). "A companionship between strangers-the hospital environment as a challenge in patient-patient interaction in oncology wards", Journal of Advanced Nursing, 70(2): 395-404.

Lee, S., Dilani, A., Morelli, A., \& Byun, H. (2007). "Health supportive design in elderly care homes: Swedish examples and their implication to Korean counterparts", Architectural Research, 9(1): 9-18.

Malkin, J. (1992). Hospital interior architecture: Creating healing environments for special patient populations. Van Nostrand Reinhold Company.

Morelli, P., Vinci, A., Galetto, L., Magon, G., Maniaci, V., \& Banfi, G. (2007). "FMECA methodology applied to two pathways in an orthopaedic hospital in Milan", Journal of Preventive Medicine And Hygiene, 48(2): 54-59.

Mour, Z. (2010). Landscape Ecology: Theory and Application. Benin: Springer.

Nasab, S. N., Azeri, A. R. K., \& Mirbazel, S. (2020). Ideal physical features of environmental design in children's hospital. Facilities.

Norton-Westwood, D. (2012). "The health-care environment through the eyes of a child-Does it soothe or provoke anxiety", International Journal of Nursing Practice, 18(1): 7-11.

Park, J. G. (2009). "Color perception in pediatric patient room design: Healthy children vs. pediatric patients", HERD: 
Health Environments Research \& Design Journal, 2(3): 628.

Pati, D., \& Nanda, U. (2011). "Influence of positive distractions on children in two clinic waiting areas", HERD: Health Environments Research \& Design Journal, 4(3): 124-140.

Pelander, T., Lehtonen, K., \& Leino-Kilpi, H. (2007). "Children in the hospital: elements of quality in drawings", Journal of Pediatric Nursing, 22(4): 333-341.

Power, N., \& Franck, L. (2008). Parent participation in the care of hospitalized children: a systematic review", Journal of Advanced Nursing, 62(6): 622-641.

Raanaas, R. K., Patil, G. G., \& Hartig, T. (2012). "Health benefits of a view of nature through the window: a quasiexperimental study of patients in a residential rehabilitation center", Clinical Rehabilitation, 26(1): 2132.

Rollins, J. A. (2015). "Medical-Legal Partnerships: Making A Difference in Children's Health Care", Pediatric Nursing, 41(1): 8-9.

Rousek, J. B., \& Hallbeck, M. S. (2011). "The use of simulated visual impairment to identify hospital design elements that contribute to wayfinding difficulties", International Journal of Industrial Ergonomics, 41(5): 447-458.

Rubin, H. R. (1998). Status report--an investigation to determine whether the built environment affects patients' medical outcomes. In Journal of healthcare design: proceedings from the... Symposium on Healthcare Design. Symposium on Healthcare Design (Vol. 10, pp. 11-13). National Symposium on Healthcare Design, Inc..

Salonen, H., Lahtinen, M., Lappalainen, S., Nevala, N., Knibbs, L. D., Morawska, L., \& Reijula, K. (2013). "Design approaches for promoting beneficial indoor environments in healthcare facilities: A review. Intelligent Buildings International, 5(1), 26-50.

Shirani, K. Z., McManus, A. T., Vaughn, G. M., McManus, W. F., Pruitt Jr, B. A., \& Mason Jr, A. D. (1986). "Effects of Environment on Infection in Burn Patients", The Journal of Burn Care \& Rehabilitation, 9(6): 678-679.

SilavUtkan, M. (2012). "Children hospital design in children Picture", Procedia-Social and Behavioral Sciences, 51: 110114.

Sinha, M., Christopher, N. C., Fenn, R., \& Reeves, L. (2006). "Evaluation of nonpharmacologic methods of pain and anxiety management for laceration repair in the pediatric emergency department”, Pediatrics, 117(4): 1162-1168.

Steinskog, D. J., Tjøstheim, D. B., \& Kvamstø, N. G. (2007). "A cautionary note on the use of the Kolmogorov-Smirnov 
test for normality", Monthly Weather Review, 135(3): 1151-1157.

Thompson, R. H., \& Vernon, D. T. (1993). Research on children's behavior after hospitalization: a review and synthesis. Journal of Developmental and Behavioral Pediatrics.

Tofle, R. B., Schwarz, B., Yoon, S., \& Max-Royale, A. (2004). Color in healthcare environments. Bonita, CA: The Coalition for Health Environments Research.

Topf, M. (2000). "Hospital noise pollution: an environmental stress model to guide research and clinical interventions", Journal of Advanced Nursing, 31(3): 520528.

Ulrich, R. S., Zimring, C., Zhu, X., DuBose, J., Seo, H. B., Choi, Y. S., ... \& Joseph, A. (2008). "A review of the research literature on evidence-based healthcare design", HERD: Health Environments Research \& Design Journal, 1(3): 61-125.

Varni, J. W., \& Katz, E. R. (1997). "Stress, social support and negative affectivity in children with newly diagnosed cancer: A prospective transactional analysis", PsychoOncology: Journal of the Psychological, Social and Behavioral Dimensions of Cancer, 6(4): 267-278.

Wilson, M. E., Megel, M. E., Enenbach, L., \& Carlson, K. L. (2010). "The voices of children: stories about hospitalization", Journal of Pediatric Health Care, 24(2): 95-102.

Ygge, B. M., \& Arnetz, J. E. (2004). "A study of parental involvement in pediatric hospital care: implications for clinical practice", Journal of Pediatric Nursing, 19(3): 217223.

Zareapour, A., Falahi Khoshknab, M., Kashaninia, Z., Biglarian, A., \& Babashahabi, R. (2009). "Effect of group play therapy on depression in children with cancer", Scientific Journal of Kurdistan University of Medical Sciences, 14(3): 64-72.

\section{Resume}

SaraNourmusavi Nasab received her B.Arch and M.Arch from Guilan University in the major of Architecture. She currently works as a researcher.

Amir Reza Karimi Azeri currently works at Guilan University, Department of Architecture, as an associate Prof. He received his M.Arch and PhD in Architecture from Iran University of science and technology.

Seyedjalil Mirbazel currently works at Guilan University, Department of Architecture, as a lecturer. He received his M.Arch in Architecture from Iran University of science and technology. 